\title{
Discussion on a big data information processing model: Taking the fiscal quality evaluation of the Pearl River Delta as an example
}

\author{
Yufeng Shi ${ }^{*}$, Jiaohui Tang and Bin Du \\ ${ }^{1}$ School of Yueshang/MBA, Guangdong University of Finance \& Economics, Guangzhou, China
}

\begin{abstract}
Under the background of vigorously promoting the high-quality economic development model in China, this paper proposes a Dynamic Double Index model to evaluate the fiscal output quality of cities in the Pearl River Delta. The empirical results show that Shenzhen, Guangzhou are at a high quality level, while Zhuhai, Foshan, Huizhou, Zhongshan and Dongguan are at a low quality level. This empirical result is consistent with the fact that Shenzhen has industrial tax source advantages, Guangzhou has consumption tax source advantages, but Zhuhai, Foshan, Huizhou Zhongshan and Dongguan do not have advantages. At the same time, the consistency also proves that the Dynamic Double Index model has accurate measurement function and can be used as a powerful tool to deal with big data information problems.
\end{abstract}

Keywords: Measurement model, Local fiscal, Pearl River Delta.

\section{Introduction}

The report of the 19th National Congress of the Communist Party of China clearly pointed out that China's economy has changed from a stage of high-speed growth to a stage of high-quality development, and there is an urgent need to change the quality, efficiency and power of China's economic development. For this reason, the academic circles have carried out fruitful research work around the high-quality question of China's economy. Among them, the research on high-quality measures mainly focuses on the wide application of two kinds of models: one is Stochastic Frontier Analysis (SFA) model (Aigner et al., 1977; Peter et al., 1981; Druska et al., 2004). This kind of model is widely used in the efficiency evaluation of economical field (Wang Pingping, 2019; Zhang Dayong et al., 2019; Zhu Fangfang, 2019). The other is Data Envelopment Analysis (DEA) (Chames et al., 1978; Fare et al., 1985; Lei et al., 1997; Su Ma, 2019), and this kind of model is also frequently used in the efficiency evaluation of managerial field (Lan Haixia, 2020; Wang Chujun et al., 2020).

From the perspective of tools, both SFA and EDA have obvious shortcomings (Kapoor et al., 2007; Afso, 2010; Tonini et al., 2011; Ma Zhanxin, 2019). The disadvantages of SFA

* Corresponding author: shiyufeng@gdufe.edu.cn 
are model setting, variable selection, randomness of variable hypothesis and complexity of parameter estimation; The disadvantage of EDA is that the measurement accuracy is not enough and the economic significance is not clear enough. In particular, there is a common defect in the above two models, that is, they all need to assume that there is an "Effective Frontier" as the "highest standard" to evaluate the input-output questions of different departments. However, from the perspective of policy evaluation, this method based on the "highest standard" is too "one-sided" and ignores the actual differences between different departments, so the evaluation results are not "scientific and reasonable".

Based on the idea of dynamic programming, this paper extends the single framework of "strong efficiency frontier" to the "double frontier" framework of "strong efficiency frontier" and "weak efficiency frontier", and then, puts forward the Dynamic Double Indexes model (DDI), so as to realize the reasonable evaluation of department input-output problems from the two dimensions of "highest standard" and "lowest standard".

The rest of this paper is divided into three chapters. The second chapter is the construction of the econometric model, which puts forward the DDI model. The third chapter is the empirical part, through the DDI model to measure the fiscal output quality of the seven cities in the Pearl River Delta. In the last part, a conclusion is made on the reliability of DDI model.

The innovation of this paper is to build a DDI model, which has the characteristics of clear economic significance and simple operation, and can accurately process all kinds of data information from different dimensions.

\section{DDI model construction}

\subsection{The definition of strong (weak) efficiency index}

The first step is to determine the reference standard. If the input-output question of variable $\alpha$ and $\beta$ of department $s$ is evaluated in period $t$, the corresponding reference standard shall be defined, denoted as $\eta_{s, t}(\alpha, \beta)$ here, and then:

$$
\eta_{s, t}(\alpha, \beta)=\sum_{k=1}^{K-1} v_{\beta, k, t} \mathrm{w}_{k, t}^{s} / \sum_{k=1}^{K-1} u_{a, k, t} \mathrm{w}_{k, t}^{s}
$$

Among, $\alpha, \beta, s, t, k, K$ respectively represents input variable, output variable, evaluated department, evaluation period, any department and the total number of departments. $w_{k, t}^{s}$ represents the dynamic weighting coefficient $\left(\sum_{k=1}^{K-1} \mathrm{w}_{k, t}^{s}=1\right), u_{\alpha, k, t}$ represents the value of the input variable $\alpha$ of department $k$ in period $t$, and $v_{\beta, k, t}$ represents the value of the output variable $\beta$ of department $k$ in period $t$.

The second step is the determination of efficiency index. If the input-output question of variable $\alpha$ and $\beta$ of department $s$ is evaluated in period $t$, an efficiency index shall be further defined, denoted as $\lambda_{s, t}(\alpha, \beta)$, and then:

$$
\lambda_{s, t}(\alpha, \beta)=\left(v_{\beta, s, t} / u_{a, s, t}\right) /\left(\sum_{k=1}^{K-1} v_{\beta, k, t} \mathrm{w}_{k, t}^{s} / \sum_{k=1}^{K-1} u_{a, k, t} \mathrm{w}_{k, t}^{s}\right)
$$


$\lambda_{s, t}(\alpha, \beta)$ is the ratio of the input-output efficiency of an evaluated department to the input-output efficiency of other reference departments. Combined with Equation (1), Equation (2) can be translated into the following form:

$$
\lambda_{s, t}(\alpha, \beta)=\left(v_{\beta, \mathrm{s}, t} / u_{\alpha, \mathrm{s}, t}\right) / \eta_{s, t}(\alpha, \beta)
$$

The third step is the definition of strong (weak) efficiency index. According to different reference standards, the definition is as follows:

When $\mathrm{w}_{k, t}^{s}=\mathrm{W}^{+}, \eta_{s, t}(\alpha, \beta)$ will get the maximum value $\eta_{s, t}^{+}(\alpha, \beta)$, and $\lambda_{s, t}(\alpha, \beta)$ will get the minimum value $\lambda_{s, t}^{+}(\alpha, \beta)$ according to Formula (3). In this case, $\lambda_{s, t}^{+}(\alpha, \beta)$ is defined as the "strong efficiency index".

When $\mathrm{W}_{k, t}^{s}=\mathrm{W}^{-}, \eta_{s, t}(\alpha, \beta)$ will get the minimum value $\eta_{s, t}^{-}(\alpha, \beta)$, and $\lambda_{s, t}(\alpha, \beta)$ will get the maximum value $\lambda_{s, t}^{-}(\alpha, \beta)$ according to Formula (3). In this case, $\lambda_{s, t}^{-}(\alpha, \beta)$ is defined as the " weak efficiency index".

\subsection{Application of strong efficiency index and weak efficiency index}

For the convenience of application, $\sum_{k=1}^{K-1} u_{a, k, t} \mathrm{w}_{k, t}^{s} / u_{\alpha, \mathrm{s}, t}$ is written as $\varphi_{\alpha, \mathrm{s}, t}$, $v_{\beta, \mathrm{s}, t} / \sum_{k=1}^{K-1} v_{\beta, k, t} \mathrm{w}_{k, t}^{s}$ is written as $\phi_{\beta, \mathrm{s}, t}$, then:

$$
\lambda_{s, t}(\alpha, \beta)=\varphi_{\alpha, s, t} \phi_{\beta, s, t}
$$

At this point, the strong efficiency index and the weak efficiency index is respectively expressed as:

$$
\begin{aligned}
& \lambda_{s, t}^{+}(\alpha, \beta)=\varphi_{\alpha, s, t}^{+} \phi_{\beta, s, t}^{+} \\
& \lambda_{s, t}^{-}(\alpha, \beta)=\varphi_{\alpha, s, t}^{-} \phi_{\beta, s, t}^{-}
\end{aligned}
$$

The above Equations (5) and (6) can be solved respectively through the following dynamic programming model:

$$
\begin{gathered}
\operatorname{Min} \sum_{t=1}^{T}\left(\sum_{\alpha=1}^{n}\left(\varphi_{\alpha, s, t} \sum_{\beta=1}^{m} \phi_{\beta, s, t}\right)\right) \\
\operatorname{Max} \sum_{t=1}^{T}\left(\sum_{\alpha=1}^{n}\left(\varphi_{\alpha, s, t} \sum_{\beta=1}^{m} \phi_{\beta, s, t}\right)\right)
\end{gathered}
$$

Wherein, $\sum_{t=1}^{T}\left(\sum_{\alpha=1}^{n}\left(\varphi_{\alpha, s, t} \sum_{\beta=1}^{m} \phi_{\beta, s, t}\right)\right)$ is the multidimensional and dynamic extended form of efficiency index $\lambda_{s, t}(\alpha, \beta)$, representing the "dynamic all-input all-output efficiency index", and the constraint condition is $\sum_{k=1}^{K-1} \mathrm{w}_{k, t}^{s}=1$. 


\subsection{The economic connotation of strong (weak) efficiency index}

According to Equation (1), when $\eta_{s, t}(\alpha, \beta)$ gets the maximum value, $\lambda_{s, t}(\alpha, \beta)$ is the strong efficiency index, and its economic connotation is the ratio of the input-output efficiency of department $S$ and the highest input-output efficiency of the reference portfolio department in the same period. It can also be understood as "the substitution coefficient for the highest input-output efficiency"; Correspondingly, when $\eta_{s, t}(\alpha, \beta)$ reaches a minimum value, $\lambda_{s, t}(\alpha, \beta)$ is the weak efficiency index, and its economic connotation is the ratio of the input-output efficiency of department $S$ in the same period to the minimum input-output efficiency of the reference portfolio department. Correspondingly, $\quad \sum_{\alpha=1}^{n}\left(\varphi_{\alpha, s, t} \sum_{\beta=1}^{m} \phi_{\beta, s, t}\right), \varphi_{\alpha, s, t} \sum_{\beta=1}^{m} \phi_{\beta, s, t}, \varphi_{\alpha, s, t} \phi_{\beta, s, t}$ are the simplified forms of $\lambda_{s, t}(\alpha, \beta)$ respectively, representing the strong (weak) efficiency index of single-input-multi-output and single-input-single-output in the case of single period.

\section{Empirical research}

\subsection{Efficiency index measurement}

In this paper, GDP, employment population, disposable income and fiscal revenue from 2009 to 2018 in Shenzhen, Guangzhou, Zhuhai, Foshan, Huizhou, Zhongshan and Dongguan are selected as input variables and output variables of DDI model respectively. Through equations (4), (7), (8) and with the help of programming language, the dynamic programming of DDI model is solved, and the strong (weak) efficiency index $\left(\varphi_{1, s, t} \sum_{\beta=1}^{3} \phi_{\beta, s, t}\right)$ value is obtained. The results are shown in Table 1 and Figure 1.

Table 1. The value of fiscal output efficiency index.

\begin{tabular}{|c|c|c|c|c|c|c|c|c|c|c|c|c|c|c|}
\hline \multirow[b]{2}{*}{ Time } & \multicolumn{7}{|c|}{ Strong efficiency index } & \multicolumn{7}{|c|}{ Weak efficiency index } \\
\hline & $\begin{array}{l}\text { Shen } \\
\text { zhen }\end{array}$ & $\begin{array}{l}\text { Guang } \\
\text { zhou }\end{array}$ & $\begin{array}{l}\text { Zhu } \\
\text { hai }\end{array}$ & $\begin{array}{l}\text { Fo } \\
\text { shan }\end{array}$ & $\begin{array}{l}\text { Hui } \\
\text { zhou }\end{array}$ & $\begin{array}{l}\text { Zhong } \\
\text { shan }\end{array}$ & $\begin{array}{l}\text { Dong } \\
\text { guan }\end{array}$ & $\begin{array}{l}\text { Shen } \\
\text { zhen }\end{array}$ & $\begin{array}{l}\text { Guang } \\
\text { zhou }\end{array}$ & $\begin{array}{l}\text { Zhu } \\
\text { hai }\end{array}$ & $\begin{array}{l}\text { Fo } \\
\text { shan }\end{array}$ & $\begin{array}{l}\text { Hui } \\
\text { zhou }\end{array}$ & $\begin{array}{l}\text { Zhong } \\
\text { shan }\end{array}$ & $\begin{array}{l}\text { Dong } \\
\text { guan }\end{array}$ \\
\hline 2009 & 3.76 & 2.41 & 1.87 & 1.33 & 1.15 & 1.25 & 1.25 & 10.84 & 8.98 & 4.76 & 4.40 & 2.78 & 3.29 & 3.66 \\
\hline 2010 & 3.81 & 2.38 & 1.85 & 1.27 & 1.16 & 1.25 & 1.23 & 10.57 & 8.62 & 4.63 & 4.10 & 2.80 & 3.26 & 3.52 \\
\hline 2011 & 4.10 & 2.20 & 1.78 & 1.21 & 1.17 & 1.40 & 1.07 & 10.39 & 7.84 & 4.91 & 3.79 & 3.16 & 3.86 & 2.97 \\
\hline 2012 & 3.97 & 2.27 & 1.87 & 1.27 & 1.30 & 1.40 & 1.14 & 9.70 & 7.59 & 4.83 & 3.70 & 3.30 & 3.66 & 2.85 \\
\hline 2013 & 4.32 & 2.10 & 2.04 & 1.33 & 1.43 & 1.44 & 1.19 & 9.37 & 6.56 & 4.96 & 3.69 & 3.48 & 3.55 & 2.81 \\
\hline 2014 & 4.82 & 1.88 & 1.93 & 1.28 & 1.48 & 1.35 & 1.14 & 10.05 & 6.31 & 5.04 & 3.64 & 3.87 & 3.48 & 3.11 \\
\hline 2015 & 5.83 & 1.55 & 1.78 & 1.10 & 1.31 & 1.20 & 1.01 & 11.42 & 5.92 & 5.27 & 3.52 & 3.83 & 3.48 & 3.11 \\
\hline 2016 & 6.44 & 1.40 & 1.70 & 1.06 & 1.22 & 1.09 & 0.94 & 12.95 & 6.04 & 5.41 & 3.71 & 3.84 & 3.39 & 3.23 \\
\hline 2017 & 6.14 & 1.47 & 1.70 & 1.13 & 1.27 & 1.15 & 0.99 & 12.79 & 6.21 & 5.17 & 3.81 & 3.77 & 3.36 & 3.28 \\
\hline 2018 & 5.97 & 1.51 & 1.74 & 1.19 & 1.25 & 1.14 & 1.04 & 13.10 & 6.45 & 4.91 & 4.00 & 3.74 & 3.14 & 3.52 \\
\hline mean & 4.92 & 1.92 & 1.83 & 1.22 & 1.27 & 1.27 & 1.10 & 11.12 & 7.05 & 4.99 & 3.84 & 3.46 & 3.45 & 3.21 \\
\hline
\end{tabular}




\subsection{Analysis of industrial structure}

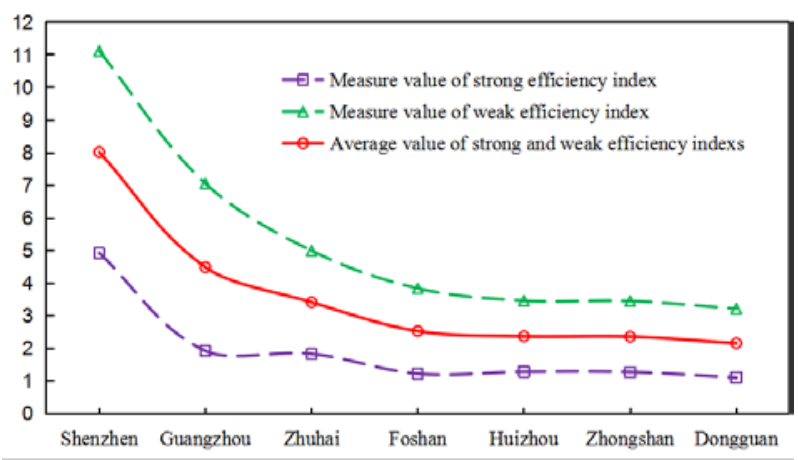

Fig. 1. The value of fiscal output efficiency index.

Table 1 and figure 1 show that the average of fiscal output efficiency indexes of Shenzhen, Guangzhou, Zhuhai, Foshan, Huizhou, Zhongshan and Dongguan are 8.0, 4.5, $3.4,2.5,2.4,2.4$ and 2.2 respectively. It can be seen that Shenzhen is far ahead of other cities, Guangzhou is second, Zhuhai is slightly lower than the average, and Foshan, Huizhou, Zhongshan and Dongguan are significantly lower than the average. Therefore, Shenzhen, Guangzhou and Zhuhai are classified as high efficiency groups (their fiscal output efficiency index values are $222 \%, 124 \%$ and $94 \%$ of the average respectively), while Foshan, Huizhou, Zhongshan and Dongguan are classified as low efficiency groups (their efficiency index values are only $70 \%$ of the average).

According to the data in Table 1, the industrial structure of seven cities in the Pearl River Delta is analyzed as follows:

(1) Shenzhen has obvious industrial advantages. Shenzhen's advanced manufacturing and high-tech industries not only account for a relatively high proportion, but also have relatively strong strength, forming a relatively large industrial cluster. Take Huawei as an example, Its 5G technology is leading the world,In 2020, its revenue is 136.7 billion US dollars, its profit is 9.9 billion US dollars, and its R\&D expenditure is 11.7 billion US dollars. In addition, there are Tencent, BYD, SF express, CNNC, ZTE, DJI, Huaxing and other world-famous manufacturers. The Government data shows that from 2011 to 2018, Shenzhen's advanced manufacturing and high-tech industries accounted for $72.1 \%$ and $67.3 \%$ of the total output value of industries above Designated Size, respectively, and the $R \& D$ investment in the same year reached more than $4 \%$, which is far ahead of other cities in the Pearl River Delta.

(2) Guangzhou and other five cities do not have industrial advantages. The industrial structure of Guangzhou is far behind that of Shenzhen, but it is superior in the consumption of residents and departments (large administration, universities and floating population); To a certain extent, Zhuhai is similar to Guangzhou (more floating population); Foshan, Huizhou, Zhongshan and Dongguan are inferior to Shenzhen and Guangzhou in both industrial structure and consumption.

\subsection{Reliability analysis of DDI model}

As shown in Figure 2, the horizontal axis is the fiscal output efficiency measurement value of the seven Pearl River Delta cities during 2009-2018, and the vertical axis is the fiscal output growth rate of the seven Pearl River Delta cities in 2019. It can be seen from the figure that except Foshan and Dongguan, the relative order of the other five cities has not 
changed, and the Pearson correlation coefficient of the seven cities is as high as 0.79 , It shows a high linear correlation (see regression line in Figure 2). The results show that: DDI model has an accurate measurement function for local fiscal output efficiency.

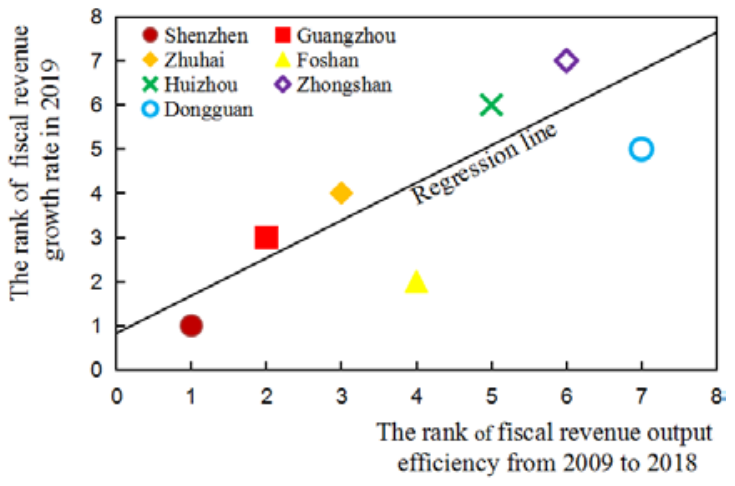

Fig. 2. Empirical test of DDI model reliability.

\section{Research conclusions}

Through the model construction, empirical research, this paper draws the following conclusions:

First of all, as shown in Figure 1, in the case of strong efficiency index, the measurement results of DDI model have little difference, while in the case of weak efficiency index, the difference is large, which shows that DDI model can take into account the weak and the strong, has good "inclusiveness" and "fairness", and has accurate measurement function.

Secondly, the fiscal output efficiency of the seven cities in the Pearl River Delta is obviously differentiated. Shenzhen is significantly ahead of other cities. It is difficult for Guangzhou, Zhuhai, Foshan, Dongguan, Huizhou and Zhongshan to catch up in the short term. Therefore, the fiscal output pattern of "one super and many strong" has been formed in the Pearl River Delta.

Third, Shenzhen continues to lead the Pearl River Delta and even the world in modern manufacturing and high-end manufacturing; Guangzhou has obvious advantages in headquarters economy, modern service industry, catering and tourism; Other cities are not dominant in manufacturing and consumption.

Fund Projects: Project of Guangdong Local Public Finance Research Center of Guangdong University of Finance \& Economics (20190007); Guangdong Education Science Planning Project (2018GXJK053).

\section{References}

1. Affuso E. Spatial Auto regressive Stochastic Frontier Analysis: An Application to An Impact Evaluation Study[J].Working Paper, Departmentof Agricultural Economicsand Rural Sociology, Auburn University, 2010.

2. Aigner D, Lovell K and Schmidt P. Formulationand Estimationof Stochastic Frontier Production Function Models[J]. Journal of Econometrics, 1977(6): 21-37.

3. Charnes A, Cooper W W and Rhddes E. Measuring the Efficiency of Decision-making Units[J]. European Journal of Operational Research, 1978(6):429-444. 
4. Druska V, Horrace W C. Generalized Moments Estimation for Spatial Panel Data: Indonesian Rice Farming[J]. American Journal of Agricultural Economics, 2004(1):185-198.

5. Fare R, Grosskopf S. A Nonparametric Cost Approach to Scale Efficiency[J]. The Scandinavia Journal of Econoics, 1985(4):594-604.

6. Kapoor M, Kelejian H H, PruchaI R. Panel Data Model swith Spatially Correlated Error Components[J]. Journal of Econometrics, 2007(1):97-130.

7. Lan Haixia, Zhao Xueyan. Spatiotemporal evolution of regional innovation efficiency and influencing factors of innovation environment in China[J]. Economic Geography, 2020(2): 97-107.

8. Ma Su, Gao liangmou, Zhao Guanghui. Research on enterprise life cycle division and efficiency based on bootstrap DEA model [J]. China Soft Science, 2019(11): 176-182.

9. Ma Zhanxin, Zhao Jiafeng. Efficiency paradox and data short tail phenomenon of DEA method [J]. Systems Engineering-Theory \& Practice, 2019(1): 200-214.

10. Pitt M, and Lee L. The Measurement and Sources of Technical Inefficiency in the Indonesian Weaving Industry[J]. Journal of Development Economics, 1981(9): 43-64.

11. Ray S C, Desli E. Productivity Growth, Technical Progress, and Eficiency Change in industrialized Comment[J]. Amerian Economic Review, 1997(5): 1033-1039.

12. Tonini A, Pede V. A Generalized Maximum Entropy Stochastic Frontier Measuring Productivity Accounting for Spatial Dependency[J]. Entropy, 2011(11): 1916-1927.

13. Wang Chujun, $\mathrm{Xu} \mathrm{Zhi}$, Chen Liyu. Evaluation of transformation efficiency of scientific and technological achievements in China's research universities based on Benchmarking Management-Application of network sequencing method[J]. Scientific Research Manageme, 2020(3): 183-193.

14. Wang Pingping, Chen Bo. Research on technical efficiency and its influencing factors of civil military integration enterprises [J]. Management review, 2019(4): 70-82.

15. Zhang Dayong, Zhang Zhiwei. Competition and efficiency: An Empirical Study Based on China's regional commercial banks [J]. Journal of Financial Research, 2019(4): 111-129.

16. Zhu Fangfang. Research on regional heterogeneity from the perspective of factor bias of innovation and technological progress-An Empirical Analysis Based on SFA and Guangdong data [J]. Journal of Applied Statistics and Management, 2019 (1): 16-27. 